\title{
Implementasi Kebijakan Layanan Pengaduan Masyarakat Secara Online di Dinas Komunikasi dan Informatika kota Pontianak
}

\begin{abstract}
The department of communication and information technology have facilitated the problems of public services complaints. The department provides an online complaint application called LAPOR! (People's Online Aspiration and Complaints Service). It can access electronic devices such as computers or laptops, smart phone, and the like. However, there are still other Organizations that provide public complaint service applications online and managed independently. It shows that the Public's complaint services are not centralized. This research uses a qualitative approach with a qualitative descriptive method. The results of the study show that It can be applied effectively if the communication aspect can synchronize well. It will be integrated and centralized in answering the community's complaints. The disposition aspect in the implementation of online public complaint services can be said to have been right on target. Employee recruitment has been arranged and determined according to their abilities and education.
\end{abstract}

\section{Key words : The Policy Implementation, Public Complaint Service.}

\section{PENDAHULUAN}

Setiap orang pastinya memiliki keluhan/permasalahan, yang masingmasing puya cara untuk mengatasi keluhannya. Namun tidak semua orang mampu mengatasinya sendiri, maka dibuatlah media/sarana untuk menyampaikan pengaduan permasalahan tersebut. Dan pengaduan bisa juga diartikan sebagai laporan yang mengandung informasi atau indikasi terjadinya penyalahgunaan wewenang, penyimpangan atau pelanggaran perilaku yang dilakukan oleh seseorang. Adapun beberapa permasalahan yang terjadi di masyarakat adalah salah satunya masalah pada ruas-ruas jalan yang beberapa lokasi masih terdapat lubang dan bergelombang, yang bisa memberikan dampak buruk bagi pengguna jalan sehingga menyebabkan kurang lancarnya arus lalu lintas, dan juga merupakan salah satu faktor penghambat dalam pembangunan kota, juga dapat mengakibatkan kecelakaan. Dan lambatnya untuk diadakan perbaikan-perbaikan pada jalan tersebut. Selain dari masalah infrastruktur pembangunan jalan, ada 
juga permasalahan seperti pelanggaran-pelanggaran yang kerap dilakukan oleh sebagian masyarakat seperti permainan layang-layang yang bukan pada tempatnya, dan segala aktifitas-aktifas masyarakat yang lainnya yang tidak diperbolehkan oleh pemerintah.

Dari permasalahan-permasalah tersebut di atas, maka perlu disediakan oleh pemerintah pusat maupun daerah untuk dapat memberikan layanan kepada masyarakat, agar masyarakat dapat menyampaikan atau melaporkan adanya suatu permasalahan yang sedang terjadi.

Untuk memfasilitasi kondisi tersebut, Pemerintah Pusat membentuk aplikasi pengaduan secara online dengan nama LAPOR! (Layanan Aspirasi dan Pengaduan Online Rakyat), yang dapat di akses melalui perangkat elektronik seperti komputer/ laptop, smartphone dan lainnya dengan alamat situs https://www.lapor.go.id/, sedangkan untuk aplikasi versi smartphone dapat diunduh pada Google Play untuk perangkat ANDROID dan App Store untuk perangkat IOS.
Mekanisme dari aplikasi LAPOR! Tersebut ialah dengan 5 proses tahapan yaitu :

1. Tulis Laporan, melaporkan keluhan atau aspirasi secara lengkap

2. Proses Verifikasi, proses ii selama 3 hari, yang diteruskan kepada instansi yang berwenang.

3. Proses Tindak Lanjut, dalam waktu 5 hari instansi akan menindaklanjuti dan membalas laporan.

4. Beri Tanggapan, Masyarakat dapat memberikan tanggapan yang diberikan oleh instansi dalam waktu 10 hari

5. Selesai, laporan akan terus ditindaklanjuti hingga terselesaikan.

Aplikasi LAPOR! Terhubung ke seluruh Instansi se-Indonesia, maka untuk mempermudah dan sekaligus mengenalkan aplikasi yang sedang dikembangkan oleh Pemerintah Daerah khususnya Pemerintah Kota Pontianak melalui Dinas Komunikasi dan Informaitka Kota Pontianak membentuk aplikasi JEPIN (Jendela Pontianak Integrasi), yang dilakukan sinkronisasi terhadap layanan pengaduan LAPOR!, sehingga dapat menyatukan setiap bentuk layanan secara online selain layanan pengaduan. 
Dengan adanya Surat Edaran Walikota Pontianak nomor 97 /DKI/2018 tentang Koordinasi, Integrasi dan Pengaturan Website, Aplikasi Online, Sistem Infromasi serta Layanan Online Lainnya dan Keputusan Kepala Dinas Komunikasi dan Informatika Kota Pontianak Nomor 49 / DKI / Tahun 2017 Tentang Pembentukan Tim Monitoring dan Evaluasi Laporan Pengaduan Pontive Center pada Dinas Komunikasi dan Informatika Kota Pontianak, maka sebagai leading sektor yang ditunjuk sebagai penanganan layanan pengaduan masyarakat secara online, Dinas Komunikasi dan Informatika Kota Pontianak, maka Pemerintah Kota Pontianak menetapkan penggunaan aplikasi mengenai layanan pengaduan masyarakat secara online tersebut dilakukan oleh Dinas Komunikasi Informatika Kota Pontianak, sedangkan untuk Perangkat Daerah lainnya yang berada di wilayah Kota Pontianak akan mengikuti instruksi dari Dinas Komunikasi dan Informatika Kota Pontianak terkait aplikasi layanan pengaduan masyarakat secara online.
Namun masih terdapat OPD yang membangun aplikasi layanan pengaduan masyarakat secara online dan dikelola oleh secara mandiri, hal ini menunjukkan bahwa layanan pengaduan masyarakat tidaklah terpusat.
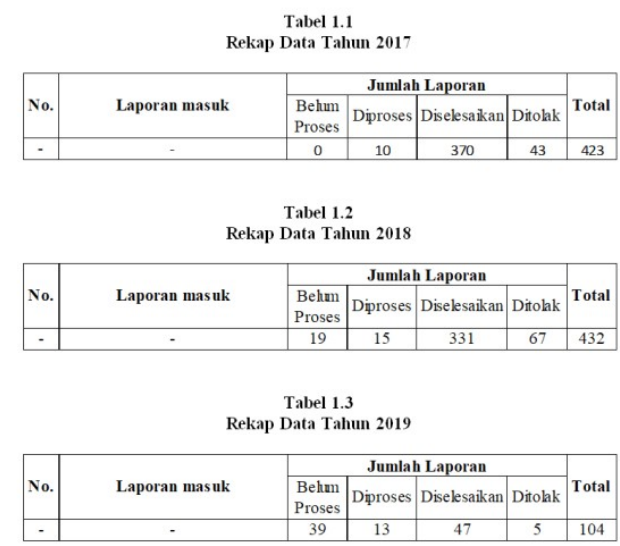

Dengan meningkatnya jumlah pengaduan yang belum diproses tampak memberikan kesan penanganan yang masih lama dan belum terselesaikan hingga sampai pada tahun berikutnya, maka hal ini menjadikan layanan pengaduan masyarakat secara online tidak benarbenar memberikan pelayanan yang smart, cepat, mudah, murah dan akurat. 
Gambar 1.1 Kerangka Pemikiran

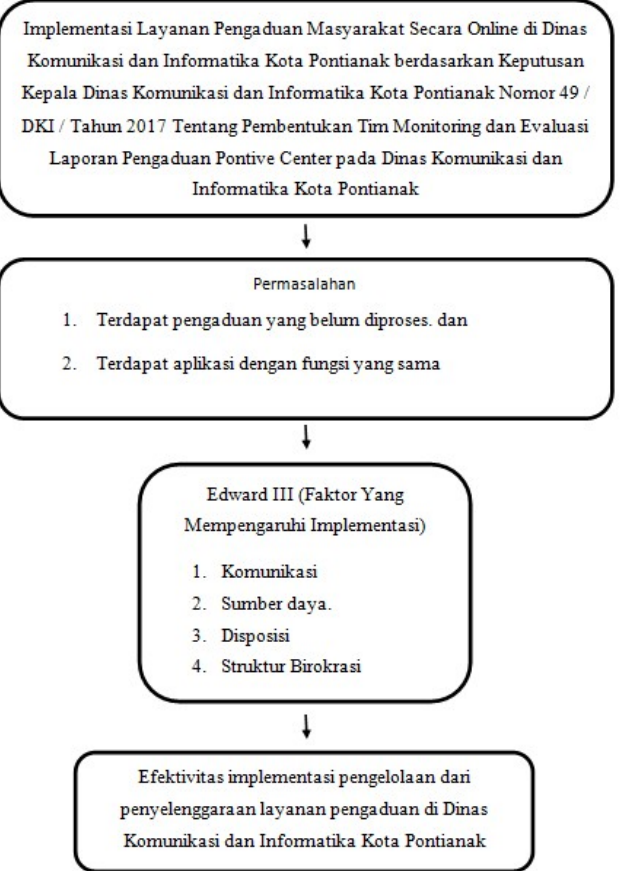

2. METODE PENELITIAN

Penelitian ini merupakan sebuah penelitian deskriptif dengan pendekatan kualitatif, Williams (dalam Meleong. 2007) mengatakan bahwa penelitian kualitatif adalah pengumpulan data pada suatu latar alamiah, dengan menggunakan metode alamiah, dan dilakukan oleh orang atau peneliti yang tertarik secara alamiah. Lebih lanjut Denzin dan Lincoln (dalam Moleong, 2007) menyatakan bahwa penelitian kualitatif adalah peneliti yang menggunakan latar alamiah, dengan maksud menafsirkan fenomena yang terjadi dan dilakukan dengan jalan melibatkan berbagai metode yang ada. Dalam penelitian kualitatif, metode yang biasanya dimanfaatkan adalah wawancara, pengamatan, dan pemanfaatan dokumen.

Lokasi yang diambil dalam penelitian ii ditentukan dengan sengaja (purposive), yang dilakukan di Dinas Komunikasi dan Informatika Kota Pontianak.

Pelaksanaan penelitian tentang implementasi layanana pengaduan masyarakat secara online di Dinas Komunikasi dan Informatika Kota Pontianak ini direncanakan pada bulan januari 2019 sampai dengan Juli 2020.

Obyek dari penelitian tentang implementasi layanana pengaduan masyarakat secara online di Dinas Komunikasi dan Informatika Kota Pontianak yang dilaksanakan oleh implementor dalam hal ini Dinas Komunikasi dan Informatika Kota Pontianak dan instansi yang terkait dalam memberikan layanan pengaduan masyarakat secara online di kota pontianak.

\section{HASIL DAN PEMBAHASAN}

Untuk melihat keberhasilan implementasi kebijakan publik tidak hanya dengan melihat keberhasilan 
dari kebijakan itu saja, namun juga melihat pada proses pelaksanaan kebijakan tersebut. Kemampuan suatu kebijakan ditentukan oleh implementabilitas kebijakan itu sendiri. Secara garis besar Edward III yang dikutip dalam buku Subarsono, Implementasi kebijakan dipengaruhi oleh empat variabel, yaitu Komunikasi, Sumber Daya, Disposisi dan Struktur Birokrasi. Dari keempat variabel tersebut merupakan suatu tolak ukur atau cara yang mana dapat mengetahui implementasi pada suatu kebijakan/keputusan itu apakah sudah berjalan dengan efektif. Keempat Variabel tersebut terdiri dari :

\section{Komunikasi}

Komunikasi merupakan elemen yang sangat penting dalam implementasi Layanan Pengaduan Masyarakat secara online di Dinas Komunikasi dan Informatika Kota Pontianak tersebut. Karena melalui komunikasi berbagai informasi yang berkaitan dengan kebijakan tersebut dapat diketahui oleh kelompok sasaran kebijakan. Implementasi layanan pengaduan masyarakat secara online di Dinas Komunikasi dan Informatika Kota Pontianak tersebut, akan optimal jika didukung oleh adanya komunikasi yang terjalin dengan baik. Implementasi kebijakan layanan tersebut akan berjalan optimal jika yang melaksanakan kebijakan tersebut memahami tugas dan wewenang serta mengerti informasi tentang Kebijakan layanan tersebut.

\section{Sumber Daya}

Faktor selanjutnya yang mempengaruhi pelaksanaan layanan pengaduan masyarakat secara online di Dinas Komunikasi dan Informatika Kota Pontianak adalah faktor sumber daya. Berdasarkan hasil wawancara langsung tersebut diatas yang ditunjang dengan hasil observasi langsung yang dilakukan oleh penulis, memperlihatkan bahwa betul selama ini bahwa memang ada kegiatan monitoring dan evaluasi terhadap pengaduan masyarakat yang dilakukan oleh Bidang Informasi dan Komunikasi Publik Dinas Komunikasi dan Informatika Kota Pontianak terkait monitoring dan evaluasi terhadap pengaduan yang belum diselesaikan.

Dari pernyataan tersebut diatas dapat dilihat bahwa telah ada upaya yang dilakukan oleh pihak Bidang Informasi dan Komunikasi 
Publik Dinas Komunikasi dan paling berpengaruh dalam Informatika Kota Pontianak selaku pelaksanaanya yakni faktor disposisi/ pengelola layanan pengaduan sikap. Menurut Edward III (1980: 90) masyarakat secara online terkait menjelaskan bahwa banyak kebijakan dengan persoalan penggunaan aplikasi layanan pengaduan masyarakat secara online di Kota Pontianak terkhusus terkait masalah monitoring dan evaluasi pengaduan yang dilakukan oleh kepada operator OPD.

Dari segi sarana dan prasarana layanan pengaduan masyarakat secara online sudah sangat baik, dilihat dari jumlah perangkat komputer dan server yang dimiliki Bidang Informasi dan Komunikasi Publik Dinas Komunikasi dan Infromatika Kota Pontianak dengan jumlah yang banyak serta pengelolaan pada ruang server yg dikhususkan untuk data center Kota Pontianak. Dan ini merupakan salah satu faktor yang mendukung berjalan pelaksanaan layanan pengaduan masyarakat secara online di Dinas Komunikasi dan Informatika Kota Pontianak.

\section{Disposisi}

Dalam implementasi layanan pengaduan masyarakat secara online di Dinas Komunikasi dan Informatika Kota Pontianak, salah satu faktor yang yang jatuh dalam zona ketidakpedulian (zone of indifference) karena orangorang yang seharusnya melaksanakan perintah memiliki pandangan perbedaan pandangan/ ketidaksetujuan dengan kebijakan.

Dari sikap implementor yakni Bidang Informasi dan komunikasi Publik Dinas Komunikasi dan Informatika Kota Pontianak dalam memberikan komitmen dalam pelaksanaan layanan pengaduan masyarakat secara online ini sudah berjalan maksimal dikarenakan semua pihak yang bertanggung jawab dalam pelaksanaanya cenderung lebih peduli dengan adanya aturan menjadi faktor pendukung dalam pelaksanaan implementasi layanan pengaduan masyarakat secara online di Dinas Komunikasi dan Informatika Kota Pontianak, meskipun terdapat OPD yang menggunakan 2 (dua) layanan pengaduan online sekaligus. Berikut ini merupakan pernyataan dari staf Bidang Informasi dan Komunikasi Publik Diskominfo Kota Pontianak 
selaku pengelolah. penggunaan layanan pengaduan masyarakat secara online di Dinas Komunikasi dan Informatika Kota Pontianak ini sangat bermanfaat dan digunakan dengan baik oleh pihak OPD-OPD yang ada di Kota Pontianak, sehingga menjadi faktor pendukung layanan pengaduan masyarakat secara online tersebut.

\section{Struktur Birokrasi}

Salah satu aspek dari struktur birokrasi yang mendukung keberhasilan implementasi kebijakan layanan pengaduan masyarakat secara online di Dinas Komunikasi dan Informatika Kota Pontianak adalah adanya Standar Operating Prosedures (SOP) yang dijalankan oleh Bidang Informasi dan Komunikasi Publik Dinas Komunikasi dan Informatika kota Pontianak dalam menjalankan tugasnya.

Salah satu hal penting yang mana hal ini sangat memegang peranan penting dalam pelaksanaan layanan pengaduan masyarakat secara online di Dinas Komunikasi dan Informatika Kota Pontianak adalah stakeholder dan masyarakat pengguna layanan. Bagaimana dua hal tersebut bisa saling memberikan kontribusi satu sama lain.
Dalam hal pelaksanaan dari pada suatu kebijakan ada hal-hal penting yang perlu untuk diperhatikan, yang mana suatu kebijakan dapat dipandang sebagai suatu sistem. Ketika kebijakan dipandang sebagai suatu sistem, maka kebijakan memiliki elemen-elemen pembentuknya.

\section{SIMPULAN DAN REKOMENDASI}

Dari hasil penelitian ini ditemukan beberapa hal terkait implementasi layanan pengaduan masyarakat secara online di Dinas Komunikasi dan Informatika Kota Pontianak, hal-hal tersebut adalah sebagai berikut :

\subsection{Simpulan}

Berdasarkan penelitian yang dilakukan, ada beberapa hal yang menjadi simpulan yaitu :

a. Komunikasi yang diimplementasikan dalam kebijakan tersebut adalah dapat berjalan secara efektif untuk tercapai tujuan dalam pengelolaan yang terpadu dan tepat dalam memberikan pelayanan pegaduan masyarakat secara online dan terpusat

b. Sumber daya yang sesuai dalam Keputusan Walikota Pontianak Nomor 732/ORG/TAHUN 2016 tentang Tim Koordinasi 
Pengelolaan Pengaduan dan Petugas Administrator pada Satuan Kerja Perangkat Daerah di Lingkungan Pemerintah Kota Pontianak tersebut adalah sudah memenuhi baik dari sisi sumber daya manusia, sumberdaya finansial dan sumber daya waktu, dan sudah sesuai yang diharapkan.

c. Disposisi yang diharapkan dalam implementasi layanan pengaduan masyarakat secara online di Dinas Komunikasi dan Informatika Kota Pontianak dapat dikatakan sudah tepat sasaran, perekrutan pegawai sudah diatur dan ditetapkan sesuai dengan kemampuan dan pendidikannya. Serta pemberian upah yang sudah sesuai dengan upah minimal regional.

d. Struktur Birokrasi pada implementasi layanan pengaduan masyarakat secara online di Dinas Komunikasi dan Informatika Kota Pontianak sudah sesuai pada prosedur yang diharapkan, yaitu tersedianya SOP (Standar Operasional Prosedur) yang harus dilaksanakan oleh setiap birokrat/ organisasi, namun perlu dilakukan peningkatan dan penegasan terhadap SOP tersebut.

\subsection{Rekomendasi.}

Berdasarkan hal tersebut di atas, maka dapat direkomendasikan bahwa keberhasilan pelaksanaan layanan pengaduan masyarakat secara online harus didukung oleh kebijakan yang memiliki implementabilitas yang tinggi. Antara lembaga pemerintah yang satu dengan yang lainnya seharusnya menetapkan sikap yang sama agar dalam pengimplementasian program dapat berjalan dengan baik.

\section{Referensi}

Abdullah, R. (2002)., Pelaksanaan Otonomi Luas \& Isu Federalisme Sebagai Suatu Alternati. Jakarta : PT. Raja Grafindo Persada.

Dunn, W. N. (2003). Analisis kebijakan Publik, : Gajah Mada University Press, Yogyakarta.

Faisal, S. (1999). Format-format Penelitian Sosial. Raja Grafindo Persada jakarta.

Miles, M. dan Huberman, A. M. (2007). Analisis Data Kualitatif: Buku Sumber Tentang MetodeMetode Baru. Jakarta.UI Press.

Moleong, 1. J. (2004). Metodologi Penelitian Kualitatif. PT. Remaja Rosdakarya. Bandung. 
Nawawi, H. (2001). Metode Peneitian Bidang Sosial. Gajah Mada University Press. Yogyakarta.

Nugroho. (2011). Kebijakan Publik untuk Negara berkembang ( Model - model perumusan Implementasi dan Evaluasi ). PT. Elex Media Komputindo. Jakarta.

Putra, F. (2001). Paradigma Kritis dalam Studi Kebijakan Publik, Pustaka Pelajar. Yogyakarta.

Sugiyono. (2009). Memahami Penelitian Kualitatif. Alfabeta Yogyakarta.

Sugiyono. (2009). Analisis Kebijakan Publik Konsep, Teori dan Aplikasi. Yogyakarta. Pustaka Pelajar.

Tilaar, H.A.R and Nugroho, R (2008). Kebijakan pendidikan: Pengantar unutk memahami kebijakan pendidikan dan kebijakan pendidikan sebagai kebijakan publik. Yogyakarta: Pustaka Pelajar.

Wahab, S. A. (2004). Analisis Kebijakan Dari Formulasi ke Implementasi kebijakan Negara. Jakarta. PT. Bumi Aksara.

\section{Publikasi dan Internet}

Rendi Saputra, Gusti Zulkifli Mulki dan Hendri Firdaus. Vol 5, No 2 (2018). Efektivitas Sistem Informasi Government And Smart City Landmark (Gencil). Jurnal Mahasiswa Teknik Sipil Universitas Tanjungpura, Pontianak
Hidana N. J.. (2018) pemanfaat Aplikasi Gencil (Government and Smart City Landmark) dalam Implementasi Konsep Smart City di Kota Pontianak. Repository UGM, Yogyakarta

\section{Perundang-Undangan}

Undang-Undang Republik Indonesia nomor 19 Tahun 2016 Tentang Perubahan Atas Undang-Undang Nomor 11 Tahun 2008 Tentang Informasi dan Transaksi Elektronik.

Keputusan Walikota Pontianak Nomor 732/ORG/TAHUN 2016 tentang Tim Koordinasi Pengelolaan Pengaduan dan Petugas Administrator pada Satuan Kerja Perangkat Daerah di Lingkungan Pemerintah Kota Pontianak

Keputusan Walikota Pontianak Nomor 567/DKI/Tahun 2017 tentang Pembentukan Tim Pengelola Pontianak Interactive Center Dinas Komunikasi dan Informatika Kota Pontianak Tahun 2017

Keputusan Kepala Dinas Komunikasi dan Informatika Kota Pontianak Nomor 49/DKI/ Tahun 2017 Tentang Pembentukan Tim Monitoring dan Evaluasi Laporan Pengaduan Pontive Center Pada Dinas Komunikasi dan Informatika Kota Pontianak. 
JPASDEV

Journal of Public Administration

and Sociology of Development

Vol. 1., N0.2., Desember 2020 